\title{
Estratégias de produção e aquisição de produtos farmacêuticos em contexto de dependência
}

\author{
Gabriela Costa Chaves 1 \\ Elaine Lazzaroni Moraes 2 \\ Claudia Garcia Serpa Osorio-de-Castro 1
}

doi: 10.1590/0102-311X00036821

Em 1899, ocorreu a epidemia de peste em Santos, São Paulo, Brasil, área portuária de grande importância para as exportações do país. Esse evento está no cerne da criação do Instituto Butantã. Como o Instituto Pasteur de Paris (França) era o único produtor de soro antipestoso e havia dificuldades para a sua rápida importação, o então diretor do Serviço Sanitário de São Paulo, Emílio Ribas, propôs ao governo da Província uma via para diminuir a dependência externa: a fundação de uma entidade produtora de soros no país 1 .

Essa história é um exemplo da busca do Brasil para se livrar da dependência na produção e na compra de bens essenciais, como medicamentos, soros e vacinas. Pena que ao longo do tempo essa dependência tenha se agudizado. O setor farmoquímico, entre outros, sofreu um processo acelerado de desindustrialização. Nos últimos 40 anos, a produção de insumos farmacêuticos ativos (IFA) caiu de 55\% para 5\%, segundo a Abiquifi (Associação Brasileira da Indústria de Insumos Farmacêuticos) 2.

Nos últimos meses, o tema tem voltado à discussão, ganhando destaque devido à necessidade de importação dos insumos para a produção das duas vacinas aprovadas para uso emergencial contra a COVID-19 no Brasil. Essa situação de dependência é mais evidente quando se sabe que, em novembro de 2020, cerca de $50 \%$ do quantitativo de vacinas em estágios avançados de desenvolvimento estavam antecipadamente reservados pelos países da União Europeia, Canadá, Estados Unidos, Reino Unido, Austrália e Japão 3, deixando descobertos os países de média e baixa rendas e levando o Diretor Geral da Organização Mundial da Saúde, Tedros Adhanom Ghebreyesus, a condenar o "nacionalismo de vacinas" 4.

A partir dos anos 2000, diferentes propostas de política industrial visaram a reverter o quadro de desindustrialização e incluíram entre seus alvos o setor farmacêutico nacional. A dependência da importação de IFA e de medicamentos, refletida numa balança comercial deficitária para o setor, sustentou o argumento da vulnerabilidade do Sistema Único de Saúde (SUS) no que se refere aos altos preços e ao fornecimento de tecnologias em saúde. Possibilitou a adoção de uma série de instrumentos para incentivar a produção, em território nacional, de insumos e produtos acabados. Entre eles estão as chamadas Parcerias para Desenvolvimento Produtivo (PDP) que, mediante a exclusividade temporária do mercado público por meio das compras de medicamentos adotada pelo SUS, buscam impulsionar
1 Escola Nacional de Saúde Pública Sergio Arouca, Fundação Oswaldo Cruz, Rio de Janeiro, Brasil 2 Coordenação de Administração Geral, Instituto Nacional de Câncer José Alencar Gomes da Silva, Rio de Janeiro, Brasil. 
transferências de tecnologia entre entes privados para os Laboratórios Farmacêuticos Oficiais (LFO) e também estimular a produção de IFA em território nacional.

O uso da compra pública como incentivo à produção nacional de medicamentos tem como um de seus marcos a alteração na legislação brasileira, a partir de 2012. Introduziu-se a possibilidade de órgãos governamentais realizarem a compra direta, tanto de insumos estratégicos para a saúde produzidos pelos LFO como de produtos estabelecidos por meio de PDP, seja em fase de transferência da tecnologia ou já como produto nacionalizado (incisos XXXII e XXXIV da Lei no 8.666/1993 5). Contudo, a Lei exige que os preços ofertados pelos LFO para essas compras diretas sejam comparáveis aos de mercado.

Tal previsão visa a dar garantia de mercado público aos LFO para atendimento das demandas do SUS. Sua efetivação, no entanto, tem enfrentado desafios, como questionamentos acerca da transparência das informações contidas nos convênios de compra, bem como no estímulo ao ambiente de "desvantagem" competitiva, para outros produtos já disponíveis no mercado nacional, e até nas dificuldades de comparabilidade de preços, o que dificulta a sua adoção por parte de gestores de compras locais.

A despeito dos avanços na publicidade dos preços praticados no mercado público nacional por intermédio de iniciativas como o Painel de Preços governamental, para fins de comparabilidade, o gestor público não encontra suficiente respaldo para efetuar a aquisição, principalmente na decisão de dispensar a licitação para adquirir um medicamento diretamente de LFO. Os preços contidos no Painel precisam ser analisados com base em parâmetros, tais como a regionalização do local de compra, devido às distorções da legislação tributária, o volume de compras e o tempo entre as aquisições, dificultando as comparações entre os valores unitários de produtos.

Esse cenário ajuda a compreender a centralidade histórica do Ministério da Saúde nas aquisições diretas, de forma prática e operacional. Portanto, reforça o papel direcionador que o seu poder de compra exerce em nível nacional, como efetivo promotor e mantenedor em qualquer iniciativa que se ampare em garantias do mercado de compras públicas, na área da saúde pública.

Contudo, ainda sob a promessa de que essas iniciativas trariam mais autonomia para o país, reduziriam as vulnerabilidades das políticas de assistência farmacêutica no SUS e fortaleceriam as capacidades de inovação, os dados indicam que a balança comercial no setor de fármacos e medicamentos continua profundamente deficitária 6 . A situação de monopólio gerada pela proteção patentária certamente contribui para os altos preços de novas tecnologias importadas e, como se pode aferir pelo momento atual, pode afetar a capacidade de produção nos diferentes países.

Ainda que o aprendizado obtido pela transferência de tecnologia pudesse viabilizar a capacitação tecnológica para inovar no futuro, e mesmo amparada pela flexibilização das aquisições deste tipo de produto pelo governo, ela não foi acompanhada de forma coordenada por investimentos em $P \& D$ e educação, fundamentais para a acumulação tecnológica. Dessa forma, o uso do poder de compra do Estado para estimular as transferências de tecnologias já existentes, como estratégia isolada, reflete uma opção governamental que mantém o país em dependência tecnológica.

Nesse sentido, o artigo Avaliação da Economicidade e da Vantajosidade nas Parcerias para o Desenvolvimento Produtivo de autoria de Alexandra Albareda \& Ricardo Lobato Torres 7 (ambos da Universidade Tecnológica Federal do Paraná), mostra a importância crítica da avaliação de novas estratégias de inovação e provisão, sob o ponto de vista da Administração 
Pública. Os resultados mostram relativa eficiência das PDP em economicidade - menores preços, maiores quantidades adquiridas - mas não seu sucesso nos aspectos relacionados à qualidade, representados pela falta de avaliação da tecnologia ou de dúvidas quanto à sua essencialidade, comprometendo a vantajosidade. Os resultados do trabalho evidenciam que a PDP como iniciativa de política pública ainda não encontrou a efetividade esperada.

É preciso reconhecer, entretanto, que embora os LFO sejam uma fatia muito pequena da indústria farmacêutica nacional, seu lugar estratégico na política de saúde tem mudado ao longo dos anos e do contexto; os laboratórios muitas vezes sendo reféns das circunstâncias em que determinadas políticas públicas os incluem (ou não) para responder às necessidades do SUS. Por essa perspectiva, o instrumento das PDP teve relevância no reconhecimento dos LFO, garantindo sua inserção nas aquisições do SUS. E a pandemia da COVID-19 tem reforçado a importância da capacidade instalada de produção para preparação e resposta oportuna às situações de crise e desabastecimento de tecnologias.

A autonomia brasileira em produção de insumos, medicamentos e vacinas ainda está longe. Mesmo assim, a produção nacional, incluindo a pública, continua sendo essencial para o sistema de saúde e para a saúde da população brasileira. As análises dos esforços recentes para incentivar a produção local são fontes valiosas de aprendizado e documentação de experiências para o presente e para o futuro, possibilitando o aperfeiçoamento e a defesa de uma política industrial orientada pelas vulnerabilidades da assistência farmacêutica no SUS, o que muitas vezes requer um enfrentamento e uma ruptura com as regras estabelecidas pela indústria farmacêutica internacional. 


\section{Colaboradores}

Todas as autoras participaram do planejamento, redação e revisão do texto.

1. Ribeiro MAR. Public health and chemicalpharmaceutical companies. Hist Ciênc SaúdeManguinhos 2001; 7:607-26.

2. Santos S. Em quatro décadas, Brasil reduz de $55 \%$ para $5 \%$ capacidade de produção de insumos farmacêuticos. Folha de S.Paulo 2021; 20 fev. https://www1.folha.uol.com.br/autores/ sheyla-santos.shtml.

3. Mullard A. How COVID vaccines are being divvied up around the world. Nature 2020; [Online ahead of print].

4. Ghebreyesus TA. Vaccine nationalism harms everyone and protects no one. Foreign Policy 2021; 2 fev. https://foreignpol icy.com/2021/02/02/vaccine-nationalismharms-everyone-and-protects-no-one/.

\section{Informações adicionais}

ORCID: Gabriela Costa Chaves (0000-0002-83476164); Elaine Lazzaroni Moraes (0000-0002-79035550); Claudia Garcia Serpa Osorio-de-Castro (0000-0003-4875-7216).

5. Senado Federal. Lei no 8.666, de 21 de Junho de 1993. Regulamenta o art. 37, inciso XXI, da Constituição Federal, institui normas para licitações e contratos da Administração Pública e dá outras providências. Diário Oficial da União 1993; 22 jun.

6. Rodrigues PHA, Costa, RDF, Kiss C. A evolução recente da indústria farmacêutica brasileira nos limites da subordinação econômica. Physis (Rio J.) 2018; 28:e280104.

7. Albareda A, Torres RL. Avaliação da economicidade e da vantajosidade nas Parcerias para o Desenvolvimento Produtivo. Cad Saúde Pública 2021; 37:e0070320. 